\title{
FUN COOKING: PEMBELAJARAN MATEMATIKA YANG MENYENANGKAN BAGI ANAK USIA DINI
}

\author{
Mirawati $^{1}$, Milah Nurkamilah ${ }^{2}$, Nandhini Hudha Anggarasari $^{3}$ \\ ${ }^{1}$ Universitas Muhammadiyah Tasikmalaya \\ ${ }^{2}$ Universitas Muhammadiyah Tasikmalaya \\ ${ }^{3}$ Universitas Muhammadiyah Tasikmalaya
}

Email : mirapaud@umtas.ac.id, milah.nurkamilah@umtas.ac.id, nandhini.hagrs@umtas.ac.id

\begin{abstract}
ABSTRAK
Artikel ini merupakan kajian literatur terkait pembelajaran matematika bagi anak melalui program fun cooking. Matematika merupakan salah satu bidang ilmu yang dipelajari di seluruh jenjang pendidikan, termasuk jenjang PAUD. Sayangnya, pembelajaran matematika pada beberapa lembaga PAUD seringkali menggunakan drill and paper pencil test, yang terkesan kaku dan monoton, bahkan cenderung memberikan tekanan bagi anak usia dini. Pembelajaran matematika di lembaga PAUD seyogyanya dapat disesuaikan dengan karakteristik anak usia dini. Pembelajaran matematika tersebut perlu dikenalkan pada anak dengan cara yang menarik dan menyenangkan. Alernatif pembelajaran matematika yang menyenangkan dapat dikemas melalui kegiatan memasak yang didesain untuk meningkatkan berbagai kemampuan matematis anak. Program fun cooking dilakukan dengan melibatkan berbagai proses matematis seperti kegiatan mengukur, berhitung dan membentuk pola kue yang akan dibuat oleh anak, sehingga diasumsikan dapat memberikan kontribusi positif terhadap berbagai aspek kemampuan matematis anak tersebut.
\end{abstract}

Kata Kunci: Fun Cooking, Matematika, Anak Usia Dini

\begin{abstract}
This article is a literature review about learning mathematics for children through fun cooking program. Mathematics is one of the areas of science learned in all levels of education, including PAUD level. Unfortunately, mathematics learning in some early childhood institutions often uses drill and paper pencil tests, which seem rigid and monotonous, even tending to put pressure on young children. Mathematics learning at PAUD institutions should be appropriate to the characteristics of early childhood. Math learning needs to be introduced to the child in an interesting and fun way. A pleasant mathematics learning algorithm can be packed through cooking activities designed to improve the child's mathematical abilities. Fun cooking program is done by involving various mathematical processes such as measuring, counting and forming cake patterns that will be made by the child, so it is assumed to give positive contribution to various aspects of mathematical ability of the child.
\end{abstract}

Key Words: Fun Cooking, Matematics, Early Childhood

\section{PENDAHULUAN}

Pembelajaran matematika bagi anak merupakan suatu sarana pengembangan kemampuan berpikir sederhana yang dapat membantu anak memahami beberapa konsep yang nyata dan bukan ditujukan agar anak memiliki keterampilan akademik sesegera mungkin (Mirawati, 2015). Hal tersebut senada dengan pendapat Sriningsih (2008) menyatakan bahwa tujuan utama dalam pengembangan pembelajaran matematika seharusnya adalah untuk menstimulasi kemampuan berpikir anak 
agar memiliki kesiapan dalam belajar matematika pada tahap selanjutnya, sehingga anak mampu menguasai berbagai pengetahuan dan keterampilan matematika yang memungkinkan mereka untuk mampu memecahkan masalah dalam kehidupan sehari-hari.

Sayangnya, saat ini tuntutan pembelajaran matematika bagi anak terutama pada jenjang taman kanakkanak justru lebih menekankan kepada penguasaan konsep dan keterampilan matematika dengan cara memberikan kegiatan yang bersifat drill dan paper pencil test (Sriningsih, 2008).

Berdasarkan uraian di atas, pembelajaran matematika bagi anak hendaknya lebih diarahkan kepada kemampuan pemecahan masalah seharihari yang ada di sekitar anak dan mampu menstimulasi berbagai potensi kemampuan matematis dalam diri anak. Salah satu program pembelajaran yang diasumsikan dapat meningkatkan kemampuan matematis anak adalah program Fun cooking. Fun cooking merupakan program pembelajaran yang diberikan pada anak melalui kegiatan memasak yang menyenangkan dengan melibatkan berbagai proses matematis seperti kegiatan mengukur, berhitung dan membentuk pola kue yang akan dibuat (Mayeski, 2002).

Berdasarkan seluruh uraian di atas, artikel ini akan mengkaji secara literatur terkait dengan penerapanprogram fun cooking dalam meningkatkan kemampuan number sense, pengukuran dan pola matematis anak, dengan tujuan dapat dijadikan sebagai salah satu alternatif pembelajaran matematika yang menyenangkan bagi anak usia dini.

\section{METODE}

Metode yang digunakan dalam penulisan artikel ini adalah literature review atau kajian berbagai sumber teori terkait dengan pembelajaran matematika dan kemampuan matematis anak, serta kajian-kajian lain yang sesuai dengan topik fun cooking sebagai salah satu alternatif pembelajaran matematika bagi anak usia dini.

\section{KAJIAN LITERATUR}

\section{A. Konsep Matematika bagi Anak Usia Dini}

Pembelajaran matematika pada dasarnya bersifat hierarkis, dengan demikian kegiatan pengembangan kemampuan matematika pun hendaknya dilakukan secara bertahap. Lorton (dalam Sriningsih, 2008) menyatakan bahwa matematika hendaknya diperkenalkan sejak dini dan merujuk pada tahapan perkembangan anak.

Pembelajaran matematika untuk anak merupakan sarana yang dapat digunakan untuk mengembangkan kemampuan berpikir, mendorong anak untuk mengembangkan berbagai potensi intelektual yang dimilikinya serta data dijadikan sebagai sarana untuk menumbuhkan berbagai sikap dan perilaku positif dalam rangka meletakkan dasar kepribadian sedini mungkin seperti sikap kritis, ulet, mandiri, ilmiah, dan rasional (Sriningsih, 2008; Rachmawati, 2008).

Ruang lingkup pembelajaran matematika bagi anak terdiri dari standar isi yang meliputi bilangan dan opreasi bilangan, aljabar, geometri, pengukuran, analisis data dan proabilitas, serta standar proses yang meliputi reasoning \& proof, problem solving, communication, dan representation (Copley, 2000; Smith, 2006).

\section{B. Fun cooking dalam Pembelajaran Matematika bagi Anak Usia Dini Fun cooking merupakan} program pembelajaran yang diberikan pada anak melalui kegiatan memasak 
yang menyenangkan. Dalam kaitannya dengan pembelajaran matematika kegiatan tersebut melibatkan berbagai proses matematis seperti kegiatan mengukur, berhitung dan membentuk pola kue atau masakan yang akan dibuat (Mayeski, 2002). Kegiatan memasak bersama dengan anak pada hakikatnya memiliki banyak manfaat, selain mengajarkan konsep matematika bagi anak usia dini, kegiatan memasak juga memiliki beberapa manfaat sebagai berikut (Mayeski, 2002; McFarland, 2017):

1. Anak-anak dapat mencoba makanan baru dan sehat. Penelitian menunjukkan bahwa anak-anak yang terlibat dalam pengalaman taktil, seperti dalam kegiatan memasak akan lebih terhindar dari ketakukan terhadap makanan tertentu (food neophobia) dan cenderung lebih mudah beradaptasi dengan beraneka ragam makanan.

2. Kegiatan memasak melibatkan semua indra secara aktif, misalnya ketika menguleni, menuangkan, mencium, memotong, dan merasakan makanan yang mereka nikmati, anak dapat belajar mengenai suatu konsep tanpa menyadarinya.

3. Kegiatan memasak dapat memperkuat "rasa keberhasilan," rasa percaya diri, dan perasaan memberikan manfaat pada orang lain.

4. Kegiatan memasak merupakan kegiatan yang melibatkan aktivitas fisik yang jauh lebih baik dibandingkan dengan bermain pasif seperti menonton, bermain games komputer dan lain sebagainya.

5. Anak-anak cenderung lebih terhindar dari jajanan yang kurang sehat, karena lebih banyak diajak untuk menyiapkan makanan atau camilan yang lebih sehat.

6. Kegiatan memasak dapat meningkatkan pengetahun anak terkait nutrisi yang ia butuhkan untuk tubuh agar lebih sehat, merencanakan makanan dan membuat pilihan makanan yang lebih baik.

7. Kegiatan memasak menyajikan pengalaman luar biasa bagi kemampuan matematis anak misalnya keterampilan matematika dasar seperti menghitung, menimbang, mengukur, melacak waktu.

8. Kegiatan memasak juga mampu menstimulasi keterampilan sosial anak adanya kerja sama dan komunikasi yang dapat dilakukan anak selama kegiatan memasak.

9. Memasak dapat membantu anakanak dalam menerima tanggung jawab. Setiap anak memiliki tugas untuk menyelesaikan persiapan dan pembersihan sisa makanan.

10. Memasak di sekolah dapat membangun kenangan positif yang mempromosikan masakan sehat dan menyenangkan di masa depan anak dalam kehidupan sehari hari.

11. Anak-anak makan lebih banyak buah dan sayuran setelah mengikuti kelas kuliner menurut beberapa penelitian.

12. Kegiatan memasak juga meyediakan pengalaman konsep sains yang dapat ditemukan dalam kehidupan sehari hari.

Berdasarkan uraian di atas, dapat terlihat bahwa kegiatan memasak ini menyediakan pengalaman belajar yang lebih bermakna, terutama dalam pengenalan konsep matematis bagi anak usia dini. 
Adapun contoh rancangan menstimulasi berbagai kemampuan matematis seperti kemampuan number sense, pengukuran, geometri dan pola matematis anak usia dini antara lain sebagai beikut:

Tabel 1. Contoh Program Fun cooking untuk Stimulasi Kemampuan Matematis pada Anak Usia Dini

\begin{tabular}{|c|c|c|}
\hline $\begin{array}{c}\text { Rencana } \\
\text { Menu }\end{array}$ & Deskripsi & $\begin{array}{c}\text { Kemampuan } \\
\text { Matematis }\end{array}$ \\
\hline $\begin{array}{c}\text { Puding } \\
\text { Berlapis }\end{array}$ & 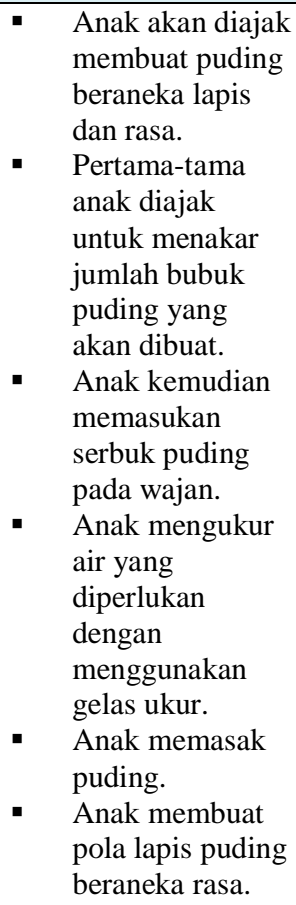 & 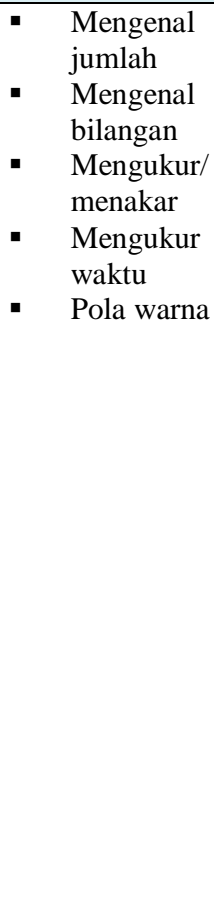 \\
\hline $\begin{array}{c}\text { Jelly } \\
\text { Geometri }\end{array}$ & 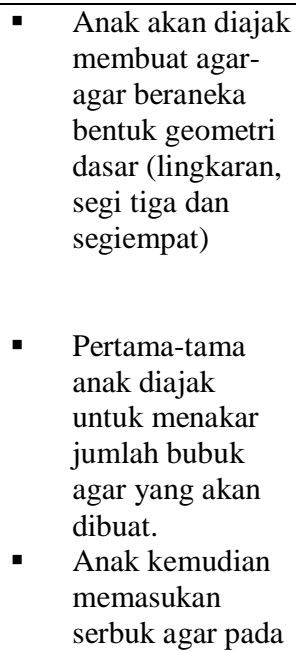 & 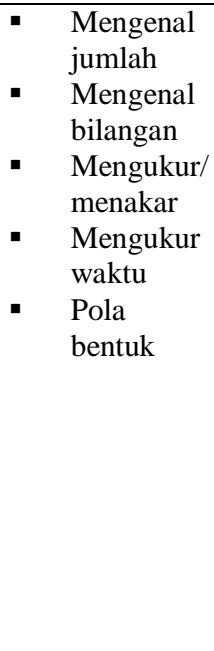 \\
\hline
\end{tabular}

\begin{tabular}{|c|c|c|}
\hline $\begin{array}{l}\text { Rencana } \\
\text { Menu }\end{array}$ & Deskripsi & $\begin{array}{c}\text { Kemampuan } \\
\text { Matematis }\end{array}$ \\
\hline & $\begin{array}{l}\text { wajan. } \\
\text { Anak mengukur } \\
\text { air yang } \\
\text { diperlukan } \\
\text { dengan } \\
\text { menggunakan } \\
\text { gelas ukur. } \\
\text { Anak memasak } \\
\text { agar } \\
\text { Anak } \\
\text { memasukan } \\
\text { agar-agar dalam } \\
\text { cetakan bentuk } \\
\text { geometri dasar. }\end{array}$ & \\
\hline $\begin{array}{c}\text { Sate Buah } \\
\text { Warna } \\
\text { Warni }\end{array}$ & $\begin{array}{l}\text { Anak akan diajak } \\
\text { membuat sate } \\
\text { buah beraneka } \\
\text { warna (Pisang, } \\
\text { Strawberry,Pepa } \\
\text { ya, Melon, } \\
\text { Mangga). } \\
\text { Pertama-tama } \\
\text { anak diajak } \\
\text { menghitung } \\
\text { jumlah jenis } \\
\text { buah yang akan } \\
\text { di jadikan sate } \\
\text { buah. } \\
\text { Anak juga } \\
\text { diminta } \\
\text { membandingkan } \\
\text { ukuran buah } \\
\text { yang telah } \\
\text { disediakan. } \\
\text { Anak diminta } \\
\text { untuk memotong } \\
\text { buah yang sudah } \\
\text { disediakan } \\
\text { (dengan } \\
\text { pengawasan } \\
\text { guru). } \\
\text { Anak kemudian } \\
\text { memasukan } \\
\text { potongan buah } \\
\text { pada tusukan } \\
\text { sate yang } \\
\text { tersedia (tusukan } \\
\text { sate yang } \\
\text { disediakan } \\
\text { didesain aman } \\
\text { /tidak berbahaya } \\
\text { Anak membuat } \\
\text { sate buah dengan } \\
\text { pola yang } \\
\text { diinginkannya. } \\
\text { Anak diajak } \\
\text { menghitung } \\
\text { jumlah sate yang } \\
\text { telah dibuat } \\
\text { bersama-sama. }\end{array}$ & $\begin{array}{ll}\text { - } & \begin{array}{l}\text { Mengenal } \\
\text { jumlah }\end{array} \\
\text { - } & \text { Mengenal } \\
\text { bilangan } \\
\text { - } \\
\text { Membandi- } \\
\text { ngkan } \\
\text { besar kecil } \\
\text { (ukuran) } \\
\text { Pola jenis } \\
\text { buah }\end{array}$ \\
\hline
\end{tabular}




\begin{tabular}{|c|c|c|}
\hline $\begin{array}{c}\text { Rencana } \\
\text { Menu }\end{array}$ & Deskripsi & $\begin{array}{c}\text { Kemampuan } \\
\text { Matematis }\end{array}$ \\
\hline $\begin{array}{l}\text { Donat } \\
\text { Pelangi }\end{array}$ & $\begin{array}{l}\text { Anak diajak } \\
\text { untuk membuat } \\
\text { hiasan toping } \\
\text { donat dari } \\
\text { beraneka ragam } \\
\text { cream beraneka } \\
\text { rasa dan warna. } \\
\text { Anak boleh } \\
\text { memilih warna- } \\
\text { warna toping } \\
\text { yang telah } \\
\text { disediakan. } \\
\text { Setelah memilih } \\
\text { anak diminta } \\
\text { untuk menghias } \\
\text { donat dengan } \\
\text { toping cream } \\
\text { berwarna yang } \\
\text { telah di pilih. } \\
\text { Anak kemudian } \\
\text { menyebutkan } \\
\text { toping warna apa } \\
\text { yang ia pilih dan } \\
\text { temannya yang } \\
\text { lain. } \\
\text { Anak juga dapat } \\
\text { menghitung } \\
\text { jumlah warna } \\
\text { dan donat yang } \\
\text { telah selesai } \\
\text { dibuat. } \\
\end{array}$ & $\begin{array}{ll}\text { - } & \text { Number } \\
& \text { Sense } \\
\text { - } & \text { Geometri } \\
\text { - } & \text { Mengenal } \\
& \text { pola warna } \\
\text { dan ukuran } \\
\text { - } \\
\text { Mengenal } \\
\text { jumlah }\end{array}$ \\
\hline
\end{tabular}

Sumber: Modul Fun Cooking (Mirawati, Milah. N.K, Nandhini. H.A, 2018)

\section{SIMPULAN}

Berdasarkan kajian literatur yang telah dipaparkan di atas, dapat diambil simpulan bahwa fun cooking merupakan salah satu kegiatan yang menyenangkan yang dapat dilakukan anak dan diasumsikan mampu menstimulasi berbagai kemampuan matematis anak seperti number sense, pola, geometri, pengukuran dan kemampuan matematis lainnya karena fun cooking tersebut didesain khusus untuk melibatkan berbagai proses matematis bagi anak. Selain itu, fun cooking juga mampu melibatkan berbagai aspek perkembangan lainnya seperti fisik-motorik, bahasa, sosial emosi, moral-keagamaan dan seni.

Menu di atas merupakan contoh program fun cooking yang dapat diterapkan untuk menstimulasi kemampuan number sense, pengukuran dan pola matematis bagi anak usia dini. Kegiatan fun cooking ini diharapkan dapat meningkatkan ketiga kemampuan matematis tersebut, terlebih lagi dapat membantu menstimulasi perkembagan anak dalam berbagai aspek lainnya agar anak dapat tumbuh dan berkembang secara optimal. 


\section{DAFTAR PUSTAKA}

Copley, J.V. 2001. The young child and mathematics. Virginia: National Council of Teachers of Mathematic.

Mayeski, M. 2002.creative activities for young children, 7th edition. United States: Delmar.

McFarland 2017. Cooking with Kids in Schools: Why It Is Important. [online] diakses dari http://articles.extension.org.

Mirawati, Milah \& Nandhini. (2018). Modul Praktik Fun Cooking bagi Anak Usia Dini. PGPAUD FKIP UMTAS.

2015. Penerapan Permainan Matematika Kreatif dalam Meningkatkan Kemampuan Number Sense Anak Usia Dini. Tesis. UPI. Tidak Diterbitkan.

Rachmawati. Y. 2008. Bahan ajar diklat pendidik anakusia dini; Matematika untuk anak usia dini. Jakarta: Direktorat Pendidikan Anak Usia Dini.

Smith, S. 2006. Early childhood mathematics, Third Edition. United States of America: Pearson Education, inc.

Sriningsih, N. 2008. Pembelajaran matematika terpadu untuk anak usia dini. Bandung: Pustaka Media. 